\title{
The Impact of Concept Mapping on Caring Efficacy of Palestinian Nursing Students at Clinical Setting
}

\author{
Dalia A. Toqan', Inaam A. Khalaf', Ahmad J. Ayed' \\ ${ }^{1}$ Faculty of Nursing, Arab American University, Jenin, Palestine \\ ${ }^{2}$ School of Nursing, The University of Jordan, Amman, Jordan \\ Email: kareemahmad2@yahoo.com
}

How to cite this paper: Toqan, D.A., Khalaf, I.A. and Ayed, A.J. (2019) The Impact of Concept Mapping on Caring Efficacy of Palestinian Nursing Students at Clinical Setting. Open Journal of Nursing, 9, 59-67.

https://doi.org/10.4236/ojn.2019.91006

Received: December 21, 2018

Accepted: January 21, 2019

Published: January 24, 2019

Copyright $\odot 2019$ by author(s) and Scientific Research Publishing Inc. This work is licensed under the Creative Commons Attribution International License (CC BY 4.0).

http://creativecommons.org/licenses/by/4.0/

\begin{abstract}
Background: The rapid change of health care delivery affirms the need for a change in the culture of nursing education through identifying the challenge to nursing faculty that many teach in the way they were taught, and suggesting a focus on the exploration of new teaching methods and student learning, rather than only focus on content coverage. Objectives: To examine the impact of concept mapping on caring efficacy of Palestinian nursing students. Methods: A quasi-experimental design, pre-post test, two groups (intervention and control group) were used. Convenience sample of 80 (40 participants in each group) nursing students from Arab American University, Jenin. Caring Efficacy was measured by Caring Efficacy Scale. The statistical tests such as t-test (independent and paired t-test) were used to examine the effect of concept mapping on caring efficacy of the fourth year nursing students at their clinical training. Results: Independent-samples t-test revealed statistically significant differences between the two groups in caring efficacy $(\mathrm{t}=$ $2.589, \mathrm{df}=78, \mathrm{P}=0.011$ ); students in the intervention group showed higher level of caring efficacy than students in the control group during their clinical training. Conclusion: Concept mapping was found to be an effective teaching method for nursing students. The use of concept mapping is useful in enhancing meaningful learning.
\end{abstract}

\section{Keywords}

Concept Mapping, Caring Efficacy, Nursing Education, Students

\section{Introduction}

The chasm between nursing practice and nursing education may never be closed 
until there is a true reformation in nursing education. Even if there were no nursing shortage or nursing faculty shortage, nursing education would still need to change dramatically to meet the demands of current nursing practice [1]. A concept-based approach in nursing curriculum opposes to surface learning; it promotes deep thinking and understanding of situations that will encounter new graduate nursing students during their nursing practice [2]. A concept map utilized in the clinical setting helps students see the whole picture by building on previous knowledge while integrating data and new information into an overall plan of care for the client. Concept mapping has a unique feature as an educational method in nursing education; it helps nursing students develop critical thinking skills, through assessing the patient, gathering information pertinent to patient's condition and relating all of this information while caring of the patient, and illustrating the information graphically [3]. The concept map has been recommended as such a tool to enhance nursing students think critically [4] [5]. Caring is considered as an essential concept which nursing students should be exposed and mentored in nursing practice. Caring is considered both a process and an outcome [6]. Although the reasons individuals offer for entering the nursing profession vary, these reasons generally focus on caring [7]. Literature emphasized that caring was usually identified by new graduated nursing students as important component for quality of the nurse [8]. For that reason, nurse educators must assert on the importance of developing caring behaviors in student nurses [7]. Hills and Watson believe that a caring science curriculum is essential in nursing curricula, which has great benefits of 1) modeling for students on how to be their best selves, 2) creating a caring environment with living relationships between faculty and students, 3) creating a space for students to have authentic dialogue with a transformation of consciousness, and 4) confirming and/or affirming the faculty member will hold the student to their highest ideal self [9]. Brown asserts that caring is mastered over time by nursing students when they keep their efforts on caring behaviors during their clinical learning [10].

According to Nelson and Watson, the concept of caring is the essence of nursing practice that links aspects of caring in nursing with the core of professional nursing, and by identifying 10 carative factors that can be measured empirically [11]. Nursing that asserts on quality patient outcomes that are guided by carative factors and grounded in a humanistic value system are what differentiate professional nursing practice from nursing practice focused solely on mechanisms or tasks. According to Watson, caritas nursing practice involves the integration of transpersonal caring and love within the context of the nurse-patient relationship and interaction, resulting in a healing and caring relationship [12].

Concept mapping is an educational method that enhances understanding the meaning of any concept included in a framework of propositions, and requires analyzing information in a learning issue and assessing reasoning processes [13] 
[14] [15]. Thus, the integration of concept mapping into teaching experience of nursing educators will lead to bridge the gap between theory and practice, improve teaching/learning outcomes, and improve meaningful learning for students. Therefore, the purpose of this study was to examine the effect of using concept mapping as an educational method on caring efficacy of Palestinian nursing students during their clinical training at the clinical settings.

\section{Hypotheses}

That nursing students taught by concept mapping will have a higher level of caring efficacy in clinical performance than those taught by regular lectures.

\section{Method}

\subsection{Design}

The study design was quantitative. A quasi-experimental pretest-posttest design was used to examine the effect of concept mapping on caring efficacy of Palestinian nursing students at their clinical settings. Two groups of fourth year nursing students were selected in an attempt to investigate the differences between them on caring efficacy based on the teaching method utilized. The control group was exposed to Human Caring Theory by traditional lecture, and the intervention group was exposed to the theory by concept mapping as a teaching method. Randomization was used to ensure that each participant had an equal chance of being assigned to the intervention or control group.

\subsection{Sample and Setting}

The target population of the current study was all nursing students in Palestine, and the accessible population was the fourth year students of academic year 2015-2016 at Arab American University, Jenin (AAUJ). Eligibility criteria included nursing students who had successfully completed the following nursing courses: communication, fundamentals of nursing, growth and development, health assessment, pediatric nursing, family health, and adult nursing.

A convenience sample, 80 students based on power analysis, using a calculated effect size of 0.5 for $t$-test to determine the differences between means of the two groups, and the power of 0.8 which is recommended based on the assumption of an expected difference resulted in a sample of 40 subjects per group. Random selection was used to assign students to either control or intervention group. This was done by selecting every other student from a list to be in intervention group beginning with No. 2 student in the list till the end of the list and the rest of students in the list were assigned to the control group.

\subsection{Data Collection Procedure}

\subsubsection{Pre Intervention Phase (Pretest)}

Prior to data collection, the researchers obtained ethical approval from the ethics committee at the School of Nursing, the University of Jordan, and the AAUJ. 
The participants were given an informed consent explaining the purpose, methods, and confidentiality of the study. Students were asked to fill the CES pretest data responses on CES were gathered before the educational presentation on Watson's human caring theory.

\subsubsection{Preparatory Phase}

\section{1) Lectures}

A two-hour lecture about human caring theory focusing on the carative factors and their application in clinical situations was presented by the same researcher to both groups to eliminate bias in instructional delivery methods. An extra two-hour lecture about concept mapping was presented to the intervention group two days after the first caring theory lecture. The lecture of concept mapping included the definition of concept mapping, benefits of concept mapping as a teaching method, benefits for students at clinical training, types of concept mapping, and concept mapping development guidelines. A diagram for concept mapping was presented and provided to students for more detailed explanation of the concept mapping developing method.

\section{2) Intervention Phase}

Students (in intervention group) were asked to utilize carative factor of $\mathrm{Hu}$ man Caring Theory in two concept mapping that include a clinical situation during their clinical training to insure their understanding of concept mapping. While the control group was asked to utilize carative factors theory without concept mapping at their regular case studies form at clinical settings. The researchers evaluated all concept maps conducted by students in order to assign scores and determine the changes in format and structure of the concept maps at the beginning and at the end of clinical training. All students in the control and intervention group received the assignments scores as a part of participation grades in the class.

3) Post Intervention Phase (Post-Test)

After receiving all concept maps, all students in both groups were asked to refill the CES.

\subsection{Instruments}

The instrument and instructions were presented in Arabic. The World Health Organization (WHO) translation protocol was used to translate instrument and training materials. The tool was first translated into Arabic by a research assistant and then translated back into English by an independent research assistant. The two English forms (the original and the translated) compared the items in conceptual terms rather than literal meanings of the primary and co-investigators who had the expertise in the field. The pilot study was done with 10 of participants from the fourth-year nursing students and they were excluded from the actual study. The tool was the Caring Efficacy Scale (CES). Based on Watson's caring theory and Bandura's self-efficacy theory, Coates (1997) developed the Caring Efficacy Scale (CES). The CES was originally had 46 items on a 6-point 
Likert scale then reduced to 30 items that consist of 23 positively worded and 7 negatively worded statements. The internal consistency of CES was 0.88 and 0.84 [16] [17]. Permission to use the CES in this study was obtained from the Dr. Jean Watson herself on behalf of Coates.

\section{Results}

\subsection{The Characteristics of the Study Participants}

The sample composed of $47(58.7 \%)$ females and $33(41.3 \%)$ was males. The majority of students had good cumulative average 39 (48.8\%), 1 (1.3\%) had excellent cumulative average, $23(28.8 \%)$ had a very good cumulative average, and $17(21.3 \%)$ had a satisfactory cumulative average and there were no participants with a weak cumulative average. The majority of participants preferred both discussion and case studied as preferable methods of teaching in clinical training $23(28.8 \%)$, followed by $18(22.5 \%)$ preferring only discussion as a teaching method, 13 (16.3\%) preferred both lectures and discussion, 6 (7.5\%) preferred lecture and discussion, 4 (5.0\%) preferred lecture, discussion, case studies, and critical thinking, $3(3.8 \%)$ preferred critical thinking and case studies as teaching methods, $3(3.8 \%)$ preferred lecture and critical thinking approach as teaching methods, $1(1.3 \%)$ preferred critical thinking approach only as a teaching method, and $1(1.3 \%)$ preferred critical thinking and discussion as teaching methods in clinical training.

\subsection{The Effect of Teaching by Concept Mapping on Caring Efficacy Level among Nursing Students}

Results of independent t-test showed that there was no significant difference in caring efficacy between the two groups pre intervention at the 0.05 level of significance $(\mathrm{t}=0.723, \mathrm{df}=79, \mathrm{P}=0.472)$. The mean for the control group was 3.11 $(\mathrm{SD}=0.25)$ and the mean for the intervention group was $3.15(\mathrm{SD}=0.20)$.

The results of independent t-test showed that there was a significant difference in caring efficacy between the groups post intervention $(t=2.589$, $\mathrm{df}=79$, $\mathrm{P}=0.011)$. The mean for the control group was $3.13(\mathrm{SD}=0.20)$ and the mean for the intervention group was $3.30(S D=0.27)$ in favor of the intervention group (students who were taught by concept mapping), which indicated that concept mapping had a positive effect on caring efficacy in students at clinical settings.

Regarding scores on the Caring Efficacy Scale (CES) posttest, the following interpretation of scale scores was used; above 3.7 is a high level of caring efficacy, between 2.5 and 3.6 is a moderate level of caring efficacy, and 2.4 or below is a poor level of caring efficacy. Most scores of the students in the control group ranged from 2.0 - 3.6, which indicated a low to moderate level of caring efficacy, whereas scores for the students in the intervention group post intervention ranged from 3.7 - 4.0, indicating a high level of caring efficacy.

To compare the mean differences in caring efficacy scores between the pre 
and post intervention period for both the control and the intervention group, paired $t$-tests were applied. The results revealed that there was no significant difference in caring efficacy scores pre and post intervention for the control group $(\mathrm{t}=0478, \mathrm{df}=39, \mathrm{P}=0.635)$, while there was a significant difference in caring efficacy scores pre and post intervention for the intervention group $(t=3.214$, $\mathrm{df}=39, \mathrm{P}=0.003)$, indicating that concept mapping was an effective teaching method for improving caring efficacy of students during their clinical training.

\section{Discussion}

Integration of nursing theoretical and practical learning experiences is important in nursing education; it aims to provide student nurses with knowledge, skills, and attitudes required for future professional practice as novice nurses [18]. Clinical practice is a vital component for nursing education at all levels of academic pursuit, especially at the baccalaureate level. Through clinical training, teachers facilitate students' application of theoretical classroom knowledge into the clinical practice setting [19] [20] [21]. The nurse educators who promote caring and utilize caring concepts may influence the way nurses will provide caring in the future [22]. Caring outcomes in practice depend on a caring teaching-learning process. Teaching caring theory leads to a transformation in thinking and practice in nursing education that is congruent with the values of caring and essential to develop the kind of nurses that are needed in today's health care system [23]. According to Watson, the nursing curriculum and the intended learning outcomes should be designed to prepare nursing students to be caring persons [12]. For that reason, Watson mentioned through her Human Caring Theory the ten carative factors that are defined as actions that could be utilized in nursing practice to improve caring relationships with patients.

The study hypothesis proposed that "students in the intervention group (fourth year nursing students who will be taught by concept map) will have higher level of caring efficacy than students in the control group (fourth year nursing students who will be taught by regular lecture) at clinical training." The results of the independent $t$-test showed that there were significant differences in caring efficacy between groups at post intervention. The mean score of the intervention group was higher than the mean score of the control group, which indicated that concept mapping had a positive effect on the level of caring efficacy of students at clinical settings. The results of the current study are consistent with Caputi and Blach (2008), Gerdeman, et al. (2014), and Wilgis and McConnell (2008), in that concept mapping was shown to be an effective method in clinical training [24] [25] [26].

Concept mapping allows students to bridge the gap between theory and clinical practice by revealing essential relationships within the clinical situation. Students in the intervention group at AAUJ utilized what was learned in the classroom on concept mapping during their training in the clinical setting. Evaluation of concept map case studies of the students in the intervention group 
showed that they were able to manage the relationships between all aspects of patient care in a holistic way. This was consistent with what was theorized by Ausubel (1978), that the role of concept mapping is to make students work with situations in a whole rather than part manner [27].

The results of the study revealed that there was no significant difference in the mean scores for caring efficacy pre and post intervention for the control group $(\mathrm{t}=0478, \mathrm{df}=39, \mathrm{P}=0.635)$, while there was a significant difference in the means pre and post intervention for the intervention group $(t=3.214, \mathrm{df}=39$, $\mathrm{P}=0.003)$. This finding indicates concept mapping was an effective teaching method for improving caring efficacy of students in the intervention group during their clinical training. The results are consistent with Caputi and Blach's (2008) study, who emphasized concept mapping as a useful tool for preparation for clinical practice [24]. By using concept maps, students are more able to bridge the gap between theory and clinical practice through revealing relationships within clinical situations.

\section{Conclusion}

The results supported the hypothesis that students educated by the concept mapping method would have higher levels of caring efficacy in their clinical training. The results showed that the students in the intervention group who were educated by concept mapping had higher mean scores on the CES posttest.

\section{Recommendations}

It is recommended to integrate concept mapping in different nursing curriculum as a mean of helping students find connections and relationships between different learned subjects.

\section{Conflicts of Interest}

The authors declare no conflicts of interest regarding the publication of this paper.

\section{References}

[1] Benner, P., Sutphen, M., Leonard, V. and Day, L. (2010) Educating Nurses: A Call for Radical Transformation. Jossey-Bass, San Francisco, CA.

[2] Giddens, J. (2007) Infusing Conceptual Learning in the Classroom and Clinical Setting. NLN Summit, Phoenix, AZ.

[3] Koehler, C.J. (2001) Nursing Process Mapping Replaces Nursing Care Plans. Fuszard's Innovative Teaching Strategies in Nursing. 3rd Edition, Aspen, Gaithersburg, MD.

[4] Schuster, P.M. (2000) Concept Mapping: Reducing Clinical Care Plan Paperwork and Increasing Learning. Nurse Educator, 25, 76-81. https://doi.org/10.1097/00006223-200003000-00009

[5] Wheeler, L.A. and Collins, S.R. (2003) The Influence of Concept Mapping on Critical Thinking in Baccalaureate Nursing Students. Journal of Professional Nursing, 
19, 339-346. https://doi.org/10.1016/S8755-7223(03)00134-0

[6] Watson, J. (2006) Caring Theory as an Ethical Guide to Administrative and Clinical Practices. Nursing Administration Quarterly, 30, 48-55. https://doi.org/10.1097/00006216-200601000-00008

[7] Eley, D., Eley, R., Bertello, M. and Rogers-Clark, C. (2012) Why Did I Become a Nurse? Personality Traits and Reason for Entering Nursing. Journal of Advanced Nursing, 68, 1546-1555. https://doi.org/10.1111/j.1365-2648.2012.05955.x

[8] Rhodes, M.K., Morris, A.H. and Lazenby, R. (2011) Nursing at Its Best: Competent and Caring. Online Journal of Issues in Nursing, 16, 10.

[9] Hills, M. and Watson, J. (2011) Creating a Caring Science Curriculum: An Emancipator Pedagogy for Nursing. Springer Publishing Company, New York.

[10] Brown, L.P. (2011) Revisiting Our Roots: Caring in Nursing Curriculum Design. Nursing Education in Practice, 11, 360-364. https://doi.org/10.1016/j.nepr.2011.03.007

[11] Nelson, J. and Watson, J. (2012) Measuring Caring, International Research on Caritas as Healing. Springer Publishing Company, New York.

[12] Watson, J. (2008) Watson's Theory of Human Caring and Subjective Living Experiences Carative Factors/Caritas Processes as a Disciplinary Guide to the Professional Nursing Practice. Danish Clinical Nursing Journal, 20, 21-27.

[13] Goldman, A. and Kane, M. (2014) Concept Mapping and Network Analysis. An Analytic Approach to Measure Ties among Constructs. Journal of Evaluation and Program Planning, 47, 9-17. https://doi.org/10.1016/j.evalprogplan.2014.06.005

[14] Tsai, M., Liange, J., Hou, H. and Tsai, C. (2012) University Students' Online Information Searching Strategies in Different Search Contexts. Australian Journal of Educational Technology, 28, 881-895. https://doi.org/10.14742/ajet.822

[15] Tseng, H.-C., et al. (2011) The Effectiveness of Problem-Based Learning and Concept Mapping among Taiwanese Registered Nursing Students. Nurse Education Today, 31, 41-42. https://doi.org/10.1016/j.nedt.2010.11.020

[16] Coates, C. (1997) The Caring Efficacy Scale. Nurses' Self-Reports of Caring in Practice Settings. Advanced Practice Nursing Quarterly, 3, 53-59.

[17] Watson, J. (2002) Intentionality and Caring-Healing Consciousness: A Practice of Transpersonal Nursing. Holistic Nursing Practice, 16, 12-19. https://doi.org/10.1097/00004650-200207000-00005

[18] Budgen, C. and Garmoth, L. (2008) An Overview of Practice Education Models. Nurse Education Today, 28, 273-283. https://doi.org/10.1016/j.nedt.2007.05.005

[19] Andrews, M. and Roberts, D. (2003) Supporting Student Nurses Learning in and through Clinical Practice: The Role of the Clinical Guide. Nurse Education Today, 23, 474-481. https://doi.org/10.1016/S0260-6917(03)00076-5

[20] Koontz, A.M., Mallory, J.L., Burns, J.A. and Chapman, S. (2010) Staff Nurses and Students: The Good, the Bad, and the Ugly. MEDSURG Nursing Journal, 19, 240-246.

[21] McKenna, L. and Wellard, S. (2009) Mothering: An Unacknowledged, Aspect of Undergraduate Clinical Teachers' Work in Nursing. Advances in Health Sciences Education, 14, 275-285. https://doi.org/10.1007/s10459-008-9109-3

[22] Ward, J., Cody, J., Schaal, M. and Hojat, M. (2011) The Empathy Enigma: An Empirical Study of Decline in Empathy among Undergraduate Nursing Students. Journal of Professional Nursing, 28, 34-40. https://doi.org/10.1016/j.profnurs.2011.10.007 
[23] O’Connor, R. and Vadasy, P. (2013) Handbook of Reading Interventions. Guilford Press.

[24] Caputi, L. and Blach, D. (2008) Teaching Nursing Using Concept Maps. College of DuPage Press, Glen Ellyn.

[25] Gerdeman, J., Lux, K. and Jacko, J. (2014) Using Concept Mapping to Build Clinical Judgment Skills. Nurse Education in Practice, 13, 11-17.

[26] Wilgis, M. and McConnell, J. (2008) Concept Mapping: An Educational Strategy to Improve Graduate Nurses' Critical Thinking Skills during a Hospital Orientation Program. The Journal of Continuing Education in Nursing, 39, 119-126. https://doi.org/10.3928/00220124-20080301-12

[27] Ausubel, D.P., Novak, J.D. and Hanesian, H. (1978) Educational Psychology: A Cognitive View. Holt Rinehart \& Winston Inc., New York. 